\title{
ANÁLISE DE FALHA EM UM CABO DE AÇO USADO EM MÁQUINAS APOLETE
}

\author{
Jorge M. Lourenço ${ }^{1}$, Fabio G. L. Pereira ${ }^{1}$, André L. de Carvalho ${ }^{2}$, Pedro A. N. Bernardini ${ }^{2}$ \\ ${ }^{1}$ Instituto Federal do Rio Grande do Norte - CNAT - Diretoria Acadêmica de Indústria \\ ${ }^{2}$ Universidade Federal de Santa Catarina - Departamento de Engenharia Mecânica \\ Jorge.magner@ifrn.edu.edu
}

Submetido 08/06/2018 - Aceito 13/08/2018

DOI: $10.15628 /$ holos. 2018.7380

\section{RESUMO}

O caso de engenharia mostrado neste artigo diz respeito a uma análise de falha envolvendo um cabo de aço. Este cabo é largamente utilizado como elemento de transmissão em uma máquina de exercícios físicos localizado, denominada de apolete. O cabo de aço emprego com essa finalidade é galvanizado, de enrolamento comum, com diâmetro de $4,8 \mathrm{~mm}$, limite de resistência de $785,34 \mathrm{~N} / \mathrm{mm}^{2}$ e fabricado pela Siva Indústria e Comércio de Artefatos de Arame e Aço Ltda. Para determinação do mecanismo que provocou a falha prematura desse elemento, os seguintes critérios de falha foram adotados: esforço de tração estática e dinâmica, de flexão pura, e por último o critério de vida teórica dos cabos metálicos, que se baseia na equação experimental de Niemam. Calculou-se a tensão admissível relacionada a cada um destes métodos. Os resultados obtidos indicaram que o cabo de aço rompeu por fadiga devido ao elevado número de ciclos de flexão ao qual foi submetido, que somado ao agravante dos movimentos invertidos, produziu uma falha prematura do material.

PALAVRAS-CHAVE: mecanismo de falha, tensão admissível, fadiga

\section{FAILURE ANALYSIS IN STEEL CABLE USED IN APOLETE MACHINES}

\section{ABSTRACT}

The engineering case showed in this paper regards to a failure analysis involving a steel cable. This cable is widely used as transmission component in fitness machines also called as apolete. This simple curling galvanized steel cable, with $4.8 \mathrm{~mm}$ in diameter, 785,34 $\mathrm{N} / \mathrm{mm}^{2}$ in tensile strength and produced by a Brazilian Company named Siva Industry Ltda is studied here. To determine the mechanism that caused premature failure of this element, the following failure criteria were adopted: static and dynamic tensile stress, pure bending stress besides useful life for steel cable which is based on the Niemam experimental equation. The permissible stress design related to each of these methods was calculated. The results indicated that the steel cable rupture was caused by the fatigue process due to the high number of cycles of blending which it was submitted. Added to that, the inverted movements produced a premature failure of the material.

KEY-WORDS: mechanism of failure, permissible stress design, fatigue 


\section{INTRODUÇÃO}

Cabos de aço são elementos com aplicações em diversos segmentos da engenharia, como na construção civil, na indústria do petróleo e gás entre outros. Esses componentes são utilizados para transmissão, reboque, elevação e/ou transporte de cargas e pessoas, como nos elevadores, e por isso seu projeto e implementação requerem elevada confiabilidade, de forma a evitar falhas e tragédias. Os cabos de aço estão sujeitos a diversas formas de desgaste, entre elas destaca-se o desgaste devido ao atrito com outros elementos de máquinas, além da submissão a cargas extremas de tração, torção, flexão pura e até mesmo fadiga (Xiang, 2015, p.234).

Diversos modos de falha de cabos de aço já foram documentados na literatura conforme Xiang (et al., 2015), Peterka (et al., 2014) e Torkar e Arzensek (2002). As falhas mais comuns ocorrem como consequência da redução da seção transversal dos fios dos enrolamentos de cabos causadas pelo desgaste por atrito, sobrecargas de tração e fadiga, ou ainda em decorrência de alterações microestruturais, principalmente a formação de martensita não revenida. Problemas de corrosão também são encontrados em cabos de aço Aragão (et al., 2014).

Uma aplicação relativamente recente dos cabos de aço é como elemento de transmissão em máquinas de exercícios físicos, particularmente em um equipamento denominado apolete. Especificamente essa máquina trabalha a hipertrofia dos músculos abdutores e glúteos. Os cabos empregados sob tais condições trabalham sob os esforços alternados produzidos pelo enrolamento e desenrolamento nas polias e tambores. Sendo assim, eles sempre estarão, inevitavelmente, submetidos à fadiga por flexão.

Diante de tais considerações, o presente trabalho tem como objetivo avaliar o comportamento dos esforços aplicados nos cabos de aço de um apolete segundo diferentes critérios, dentre eles: esforço de tração estática e dinâmica, de flexão pura e por fim o critério de vida teórica baseado na equação experimental de Niemam, e assim, determinar, através do cálculo da resistência admissível, qual tipo de solicitação mecânica foi determinante para a falha do material.

\section{MATERIAIS E MÉTODOS}

2.1 Descrição do equipamento e especificação do material analisado.

A seguinte análise de engenharia consiste na ruptura de um cabo de aço usado numa máquina de exercícios localizados. Este equipamento é comumente denominado de apolete, veja figura 01. Projetou-se tal máquina para desenvolvimento dos músculos abdutores e glúteos. 


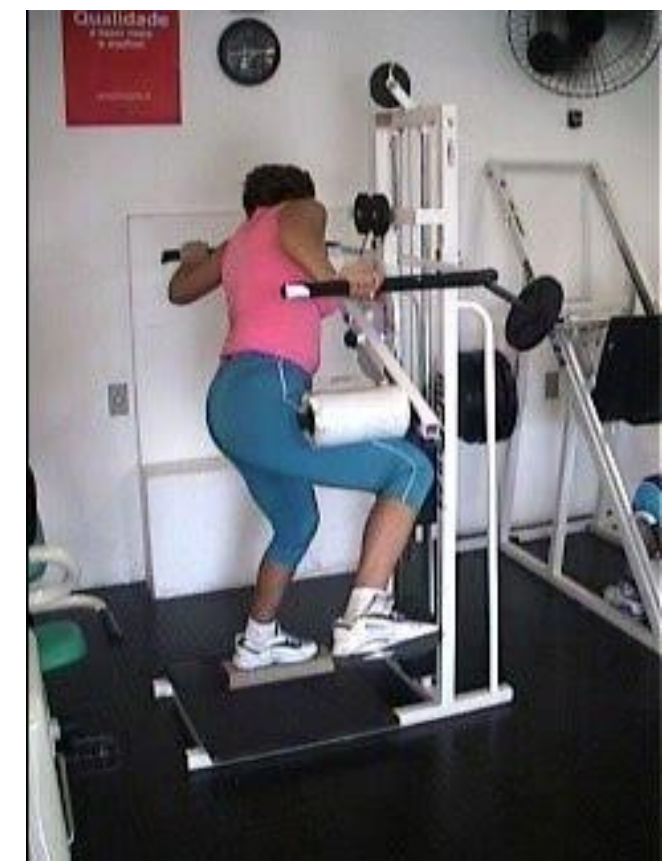

Figura 01 - Atleta exercitando músculo abdutor

O apolete em discussão tem montagem vertical fazendo com que cada atleta exercite por etapa cada músculo e/ ou cada perna, fazendo com que haja uma maior solicitação mecânica do cabo de aço. Para execução do exercício da musculatura abdutora, o atleta posiciona-se de frente para a máquina com as mãos apoiadas em dois fixadores existentes no equipamento e com a coxa fixada numa almofada, transferindo movimentos alternados lateralmente ao bloco de pesos através de um cabo de aço para duas polias de diâmetros $\phi=110 \mathrm{~mm}$ e uma última polia grande de diâmetro $\phi=350$ $\mathrm{mm}$. Repete-se os mesmos movimentos em sentido oposto com a outra perna, geralmente três séries de dez movimentos para cada perna. Os mesmos movimentos são repetidos para a execução do exercício de glúteo, porém com um curso maior. Nesse caso, o atleta posiciona-se de lado da máquina e com o tronco semi-flexionado transfere movimento alternado ao bloco de pesos, repetindo-se os mesmos movimentos em sentido oposto com a outra perna, geralmente três séries de dez exercícios, veja a figura 02 .

Dessa forma, o cabo completa um ciclo com cada repetição de exercício. Para ajustar o equipamento a atletas de diferentes tamanhos, a alavanca permite ajuste da almofada fixadora através de um parafuso que se move ao longo de um rasgo. Para trocar de perna existe um ajuste da alavanca com a polia grande em diversos furos ao longo de $180^{\circ}$, que através de um pino de aço, permite-se tal regulagem. Os pesos que esse cabo de aço suporte constituem-se de 14 blocos de ferro fundido de $5 \mathrm{~kg}$ cada.

De acordo com as especificações técnicas do equipamento, o material utilizado na análise foi um cabo de aço fabricado pela empresa Silva indústria e comércio de artefatos de arame e aço LTDA, com tipo de rolamento comum, diâmetro $\varnothing=4,8 \mathrm{~mm}$ e alma de fibra de aço galvanizado. $O$ limite de resistência do material é igual a $785,34 \mathrm{~N} / \mathrm{mm}^{2}$, o passo do toro é igual a $34 \mathrm{~mm}$ e o passo do fio é igual a $15 \mathrm{~mm}$. Esse cabo de aço estará sujeito a uma solicitação máxima de $70 \mathrm{Kg}$, que corresponde a 14 blocos de $5 \mathrm{Kg}$ cada. 


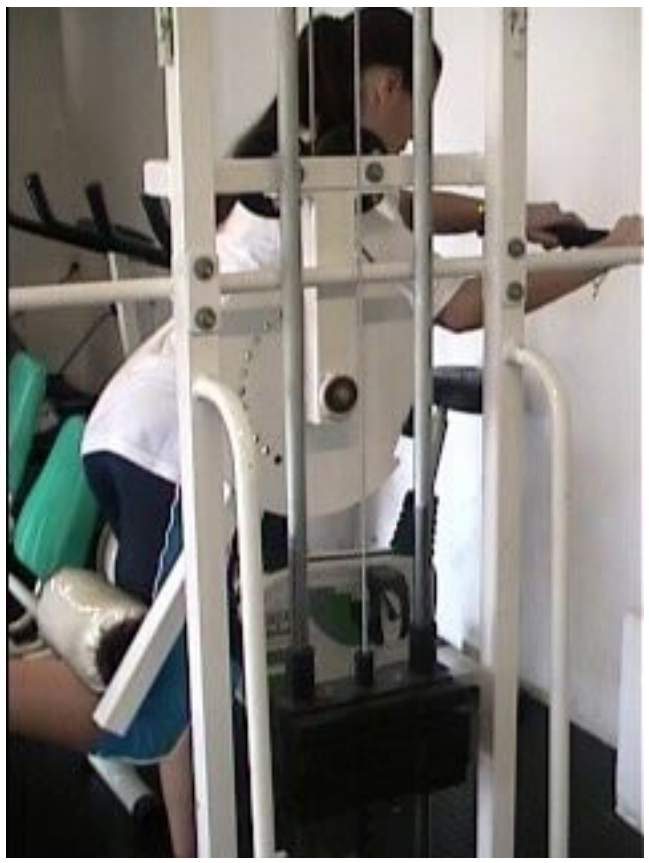

Figura 02 - Atleta exercitando músculo glúteo

\subsection{Critérios de análise.}

Os critérios que determinam o quanto os cabos são capazes de suportar uma carga, quando em serviço, podem ser divididos em: esforço de tração estática, esforço de tração dinâmica, esforço de flexão pura e vida dos cabos metálicos. Todos esses critérios compreendem as maneiras como uma força pode ser aplicada em um corpo (Budynas, 2011). A partir da aplicação desses quatro critérios e a comparação com limite de resistência do material, foi possível determinar qual tipo de solicitação mecânica levou ao rompimento do cabo.

\subsubsection{Esforço de tração estática.}

Esse critério considera uma solicitação mecânica que tende a alongar uma peça no sentido do eixo de ação da força externa aplicada. Além disso, considera-se que a carga é constante ao longo do tempo e é aplicada de forma lenta e gradual sobre o cabo de aço (Coelho, 1988).

Assim, a aplicação de uma força externa $\mathbf{P}$ gera uma tensão admissível $\left(\sigma_{a d m}\right)$ dada pela equação (1).

$\sigma_{a d m}=\frac{P}{S}$

Onde S é a área da seção transversal do cabo de aço de diâmetro d. Essa área é calculada a partir da equação (2).

$$
S=\frac{\pi d^{2}}{4}
$$

2.2.2 Esforço de tração dinâmica 
Esse critério ainda considera uma solicitação mecânica que tende a alongar uma peça no sentido do eixo de ação da força externa aplicada. Entretanto, nesse caso, a carga aplicada não é constante ao longo do tempo. Esse tipo de carregamento é chamado intermitente. Ocorre quando a peça está sujeita a uma carga variável positiva, que varia de zero a um valor máximo, sempre na mesma direção e sentido (Cunha, 2005).

Assim, a aplicação de uma força externa $\mathrm{P}$ gera uma tensão dinâmica $\left(\sigma_{\text {dim }}\right)$, dada pela equação (3), que é função da tensão de tração estática.

$\sigma_{\text {dim }}=0.10 \sigma_{\text {est }}$

Nesse critério a carga considerada é o esforço total combinado entre carga dinâmica e estática. Logo:

$\sigma_{\text {tot }}=\sigma_{\text {dim }}+\sigma_{\text {est }}$

\subsubsection{Esforço de flexão pura}

Esse critério considera uma solicitação mecânica que tende a modificar o eixo geométrico de uma peça. No caso analisado essa modificação do eixo geométrico o ocorre nas regiões em que o cabo de aço está em contato com as polias (Jones, 1993).

Assim, a tensão de flexão $\left(\sigma_{f}\right)$ é dada pela equação (5), e é função do módulo de elasticidade (E), o diâmetro do cabo de aço (d), o diâmetro da polia (D), o ângulo de enrolamento do arame $(\alpha)$ e o ângulo de enrolamento do toro $(\beta)$.

$\sigma_{f}=\frac{E \cdot d \cdot \cos ^{2} \alpha \cdot \cos ^{2} \beta}{D}$

\subsubsection{Vida dos cabos metálicos}

A fadiga exerce influência sensível sobre a vida dos cabos (Bernardini, 2001). Uma vez que os cabos trabalham sob os esforços alternados produzidos pelo enrolamento e desenrolamento nas polias e tambores, estarão inevitavelmente submetidos à fadiga por flexão; mas podem-se projetar montagens onde tais esforços sejam sempre alternados - já que isto é inevitável - mas não invertidos, com que a fadiga seria mais acentuada. Esse fato explica basicamente toda a falha do cabo da máquina apolete, já que esta possui esforços alternados e invertidos (Vernon, 1999).

A determinação da vida de um cabo metálico sob tais circunstâncias pode ser realizada a partir da equação experimental de Niemamm, dada pela equação (6).

$$
\frac{W}{1000} \cong 170 \cdot\left|\frac{b_{1} \cdot b_{2} \cdot\left[\frac{D}{d}-\frac{9}{b_{1}}\right]}{4+\sigma}\right|^{2}
$$


Onde $\mathrm{W}$ é o número de flexões as quais o cabo é submetido até a ruptura, $\mathrm{D}$ é o diâmetro da polia, d é o diâmetro do cabo, $\sigma$ é a tensão atuante no cabo em $\mathrm{kgf} / \mathrm{mm}^{2}, b_{1}$ é um fator de forma do borne e $b_{2}$ é um fator de enrolamento do cabo.

\subsection{Fator de segurança}

O fator de segurança é a relação entre a tensão de ruptura $\sigma_{\text {rup }}$ e a tensão admissível $\sigma_{a d m}$, conforme mostrado na equação (7). Trata-se de um número sempre maior que 1 , de forma a garantir a menor possibilidade de falha de componentes de engenharia. Valores específicos dependem dos tipos de materiais usados e da finalidade pretendida da estrutura ou máquina (Budynas, 2011).

$F . S=\frac{\sigma_{r u p}}{\sigma_{a d m}}$

\section{RESULTADOS E DISCUSSÃO}

A seguir são apresentados os cálculos realizados para a obtenção de uma estimativa da resistência admissível do material sob os diferentes tipos de solicitação mecânica avaliados, entre eles: esforço de tração estática, esforço de tração dinâmica, esforço de flexão e o critério de vida dos cabos metálicos. Esses resultados serão comparados com o valor de resistência do material retirado das especificações técnicas do equipamento.

\subsection{Esforço de tração estática}

A tensão admissível obtida pelo critério do esforço de tração estática é obtida a partir da aplicação da equação (1). Considerando que o número máximo de blocos comportados pelo equipamento é 14 e que cada bloco tem massa de $5 \mathrm{Kg}$, a massa total que o cabo de aço terá de suportar é de $70 \mathrm{Kg}$. Sendo assim, adotando uma aceleração da gravidade de $9,81 \mathrm{~m} / \mathrm{s}^{2}$, o peso total aplicado sobre o cabo de aço será de 686,7 N. Além disso, de acordo com as especificações técnicas do equipamento, o diâmetro do cabo de aço é de $4,8 \mathrm{~mm}$. Logo, aplicando a equação (2) a área da seção transversal será de $18,10 \mathrm{~mm}^{2}$.

Assim, a partir da aplicação da equação (1) obtém-se uma tensão admissível de $37,94 \mathrm{~N} / \mathrm{mm}^{2}$. Sabendo que o limite de resistência do fabricante fornecido pelo fabricante é de $785,34 \mathrm{~N} / \mathrm{mm}^{2}$ e comparando a tensão estática máxima aplicada $\left(37,94 \mathrm{~N} / \mathrm{mm}^{2}\right)$ com esse limite fica evidente que a solicitação é bastante inferior a capacidade do cabo. Logo, pode-se afirmar que a solicitação de tração estática não é suficiente para provocar a falha do cabo de aço.

A aplicação da equação (7) mostra que o fator de segurança para o critério de tração estática é aproximadamente igual a 20.

\subsection{Esforço de tração dinâmica}

A tensão admissível obtida pelo critério do esforço de tração dinâmica é obtida a partir da aplicação da equação (3). Aqui também se utiliza o valor de peso total aplicado sobre o cabo de aço de 
686,7 N (referente aos 14 blocos de $5 \mathrm{Kg}$ ). Nesse critério a tensão admissível considera a soma das componentes estática e dinâmica como destacado na equação (4).

Assim, a partir do valor da tensão admissível estática obtido no tópico 3.1 e aplicando a equação 3 , obtém-se uma tensão admissível dinâmica igual a $3,8 \mathrm{~N} / \mathrm{mm}^{2}$. Portanto, a tensão admissível total, descrita na equação 4 , será igual a $41,47 \mathrm{~N} / \mathrm{mm}^{2}$.

Do mesmo modo, comparando a tensão total calculada $\left(41,47 \mathrm{~N} / \mathrm{mm}^{2}\right)$ com o limite de resistência do fabricante $\left(785,34 \mathrm{~N} / \mathrm{mm}^{2}\right)$, fica evidente que a solicitação é bastante inferior a capacidade do cabo, resultando em um coeficiente de segurança da ordem de 19. De forma tal que é possível garantir que o esforço de tração dinâmica não é suficiente para provocar a ruptura do material.

A aplicação da equação (7) mostra que o fator de segurança para o critério de tração dinâmica é aproximadamente igual a 19.

\subsection{Esforço de flexão pura}

A tensão admissível obtida pelo critério do esforço de flexão pura é obtida a partir da aplicação da equação (5). Aqui as considerações são basicamente geométricas e estão relacionadas aos diâmetros das polias, do cabo de aço $(4,8 \mathrm{~mm})$ e aos ângulos de enrolamento do $\left(45^{\circ}\right)$ arame e de enrolamento de toro $\left(45^{\circ}\right)$. Além disso, depende também do módulo de elasticidade do cabo de aço que segundo as especificações técnicas do fabricante é de $10800 \mathrm{MPa}$.

Como existem duas regiões que provocam a flexão do cabo de aço e essas regiões apresentam polias com diâmetros diferentes é necessário realizar os cálculos para essas duas regiões. Portanto, aplicando a equação (5) para as polias de 110 e $350 \mathrm{~mm}$ obtém-se, respectivamente, tensões admissíveis de flexão pura iguais a 117,81 e $37,03 \mathrm{~N} / \mathrm{mm}^{2}$.

Comparando a tensão de flexão acima, utilizando os diâmetros das duas polias $\left(117,81 \mathrm{~N} / \mathrm{mm}^{2}\right.$ e $37,03 \mathrm{~N} / \mathrm{mm}^{2}$ ), com o limite de resistência do fabricante $\left(785,34 \mathrm{~N} / \mathrm{mm}^{2}\right)$, fica mais uma vez comprovado que a solicitação por flexão é bastante inferior a capacidade do cabo, logo o esforço de flexão pura não é suficiente para provocar a ruptura do cabo de aço.

A aplicação da equação (7) mostra que o fator de segurança para o critério de flexão pura é aproximadamente igual a 7 para o caso da polia de menor diâmetro.

\section{Vida dos cabos metálicos}

A tensão admissível obtida pelo critério da vida dos cabos metálicos é obtida a partir da aplicação da equação (6). Ao contrário dos casos anteriores, esse método determina o número de ciclos de flexão (W) suportados pelo material até a ruptura. Novamente, esse esforço está localizado na região de contato entre o cabo de aço e a polia.

O cabo deve ser projetado de modo a resistir um determinado número de flexões. Entendese por flexionamento a transformação de um trecho retilíneo em curva com a movimentação do cabo em serviço. A passagem de ida e volta de um cabo por uma polia corresponde então a um flexionamento. Acontece que a máquina apolete abordada, apresenta flexionamentos alternados e invertidos em torno da polia menor, ou seja, o cabo rotaciona nos sentidos horário e anti-horário, veja a figura 3. 
Esta situação é o equivalente a 1,5 flexionamentos para cada ciclo de trabalho do cabo, devido ao movimento invertido deste. Este fator de correção 1,5 é válido para cabos de enrolamento regular, que é o utilizado no equipamento apolete em questão.
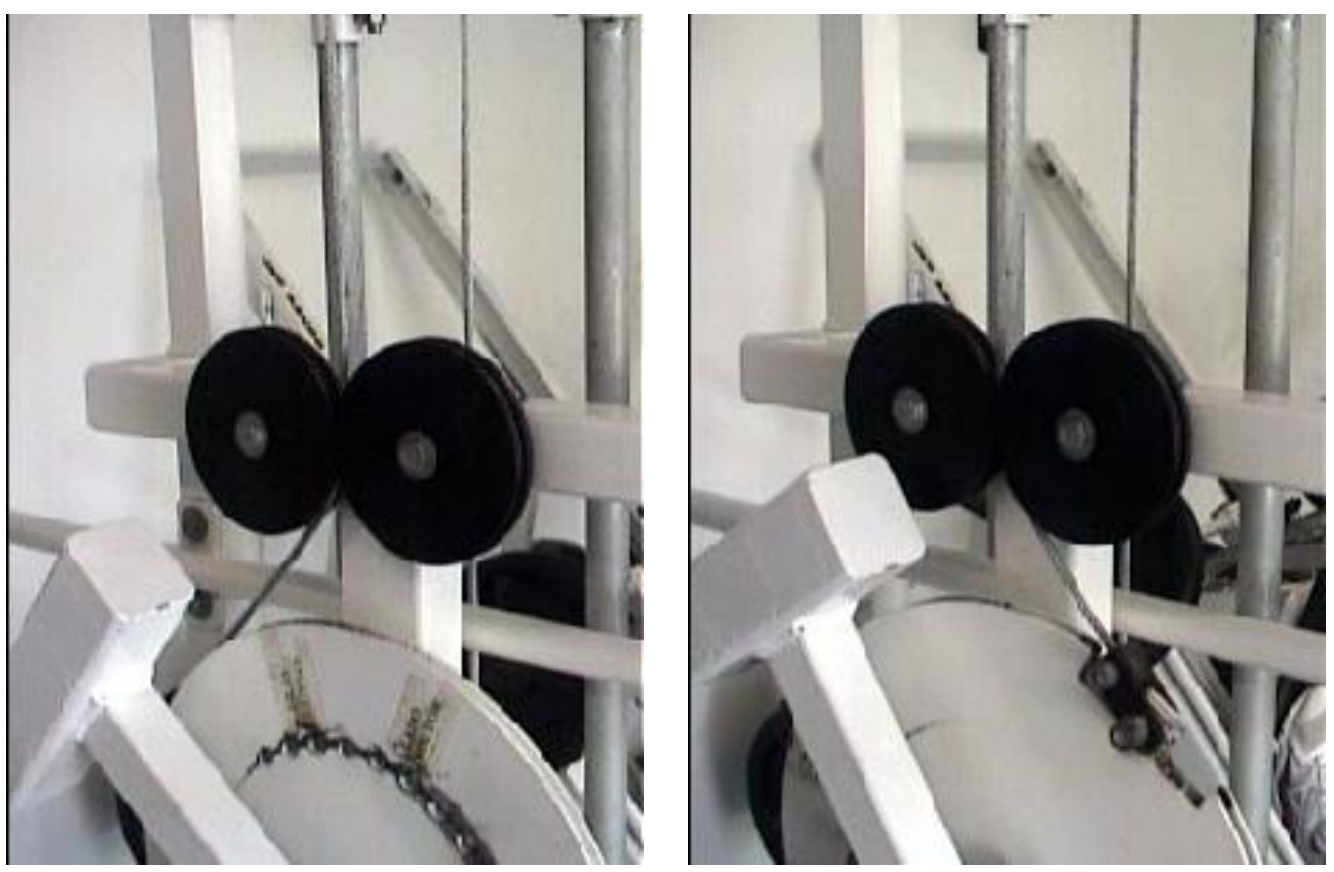

Figura 3 - Região da fratura com movimentos alternados e invertidos

Assim, considera-se o diâmetro da polia $\mathrm{D}$ igual a $110 \mathrm{~mm}$. O diâmetro do cabo é de 4,8 m, a tensão atuante no cabo em decorrência do peso total, em $\mathrm{kgf} / \mathrm{mm}^{2}$, é de 1815 . Já os valores de forma $b_{1}$ e $b_{2}$, valores tabelados, são iguais a 0,72 e 1,04 respectivamente. Logo aplicando a equação (6) obtém-se um número de ciclos igual a 305871,27 . Esse valor é corrigido dividindo-o por um fator de correção igual a 1,5. Logo, o número de ciclos real é igual a 203914.

Portanto, esse critério estabelece que o cabo de aço é capaz de suportar até 203914 ciclos de flexão sob essas condições especificadas.

A figura 4 mostra a falha ocorrida no cabo exatamente na região descrita acima, esta tem característica de falha por flexão, onde é percebido uma curvatura na região da falha. 

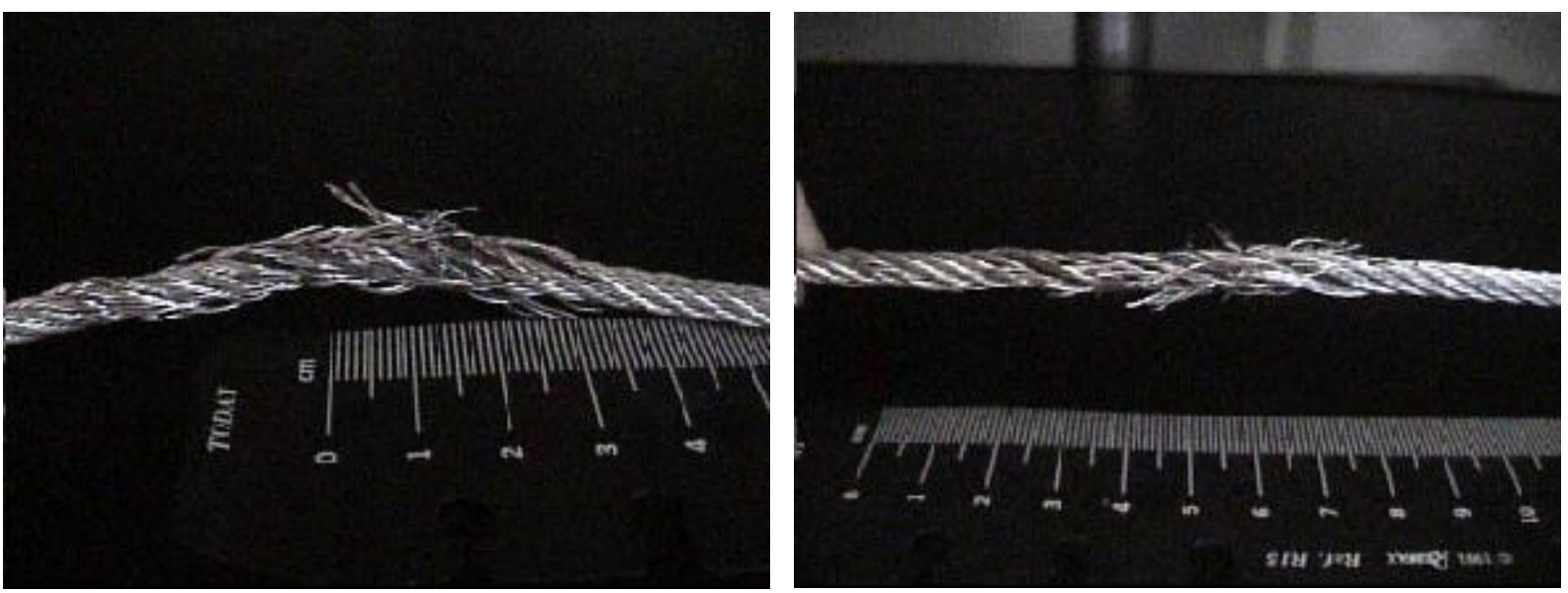

Figura 4 - Ruptura do cabo de aço da máquina apolete

A figura 5 mostra a região da falha sem solicitação mecânica. Esta região em repouso quando solicitada a esforços será flexionada entre as polias, tanto em movimento alternado como invertido, motivando a ruptura prematura do cabo de aço.

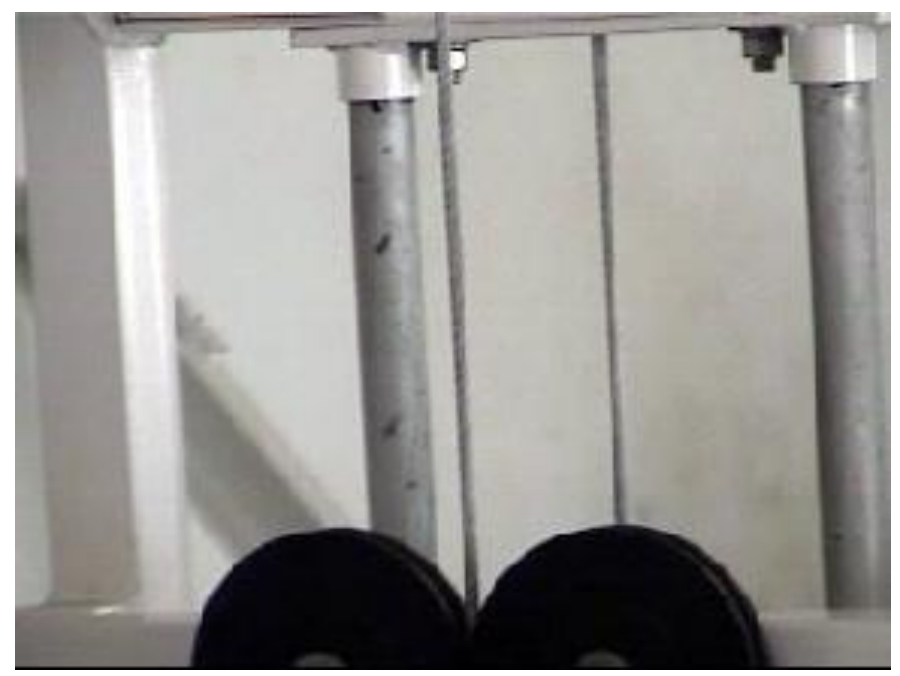

Figura 5 - Região da falha em repouso

Deste modo, conclui-se que a vida de flexão naquela região do cabo será inferior à do restante do cabo, como foi observado que realmente o cabo sempre rompe naquela região, existindo evidências de que a razão da ruptura do cabo é o fim de vida em flexão.

Baseado na equação experimental de Niemam, que limita um determinado número ciclos de flexões para o cabo, partiu-se para comprovação deste fato com base em parâmetros reais como: frequência de uso pelos atletas, blocos de pesos mais utilizados, tipo de exercício e frequência de ruptura do cabo nos últimos seis meses.

Observou-se que o cabo de aço deste equipamento rompe-se a cada três semanas, ou seja, aproximadamente a cada vinte e um dias. Destes dias em questão, apenas nove dias são efetivamente 
dias de exercícios, devido aos finais de semanas. Cada atleta frequenta em média três vezes por semana, executando três séries de dez repetições para cada tipo de exercício. O número de atletas regularmente inscrito na academia é conhecido, veja figura 6 .
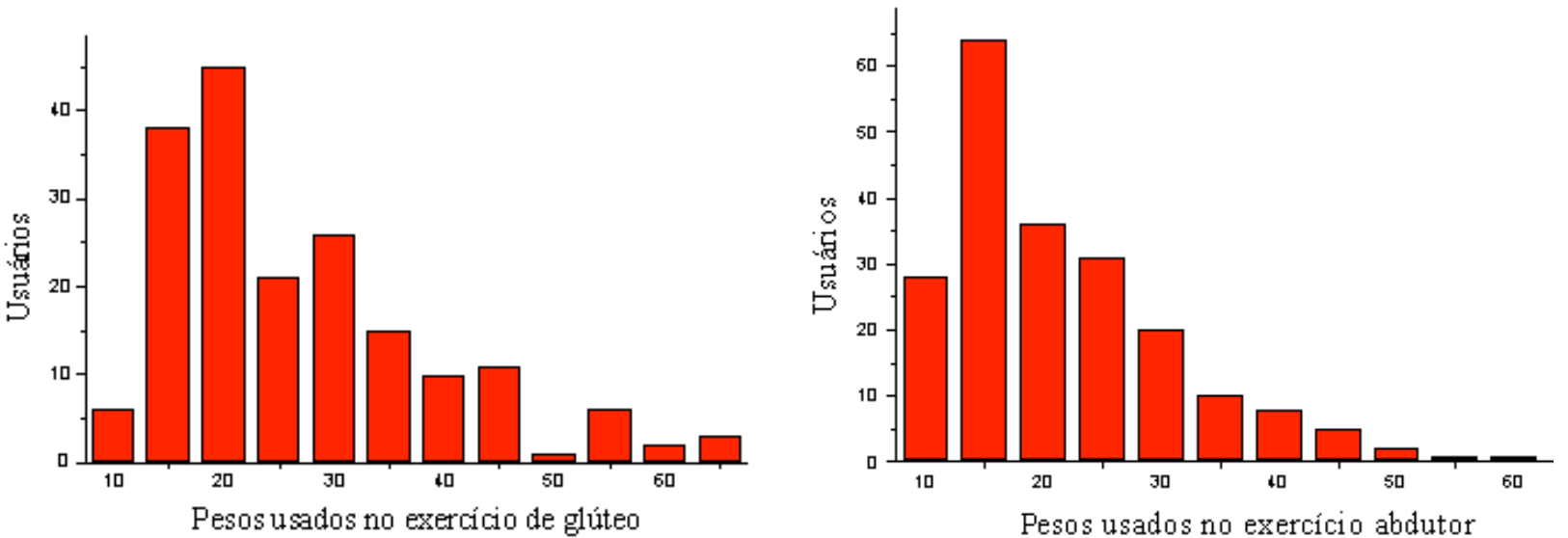

Figura 6 - Estatística do número de atletas

São 216 atletas que executam o apolete para musculatura abdutora; e 195 atletas que executam para glúteo, cada um efetivando 30 repetições para cada perna e tipo de exercício, veja figura 7.
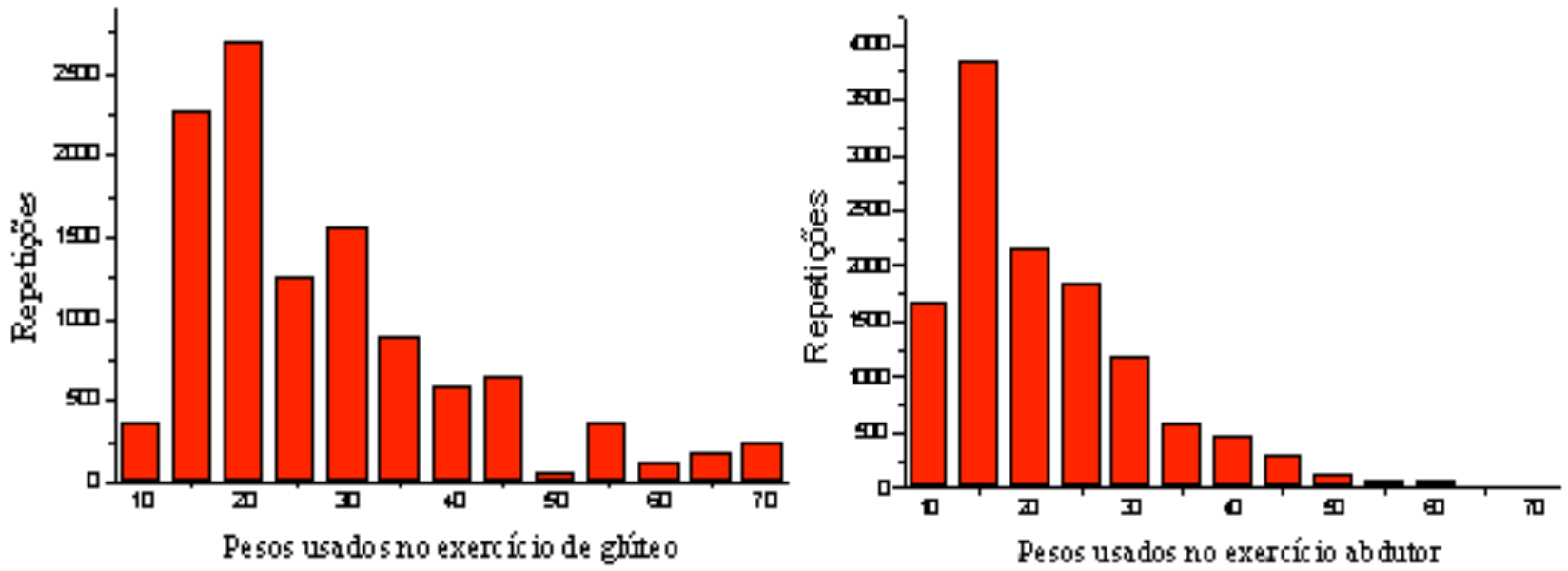

Figura 7 - Números de repetições

Portanto, verifica-se que o número de ciclos de flexão é igual ao número de repetições multiplicado pelo número de dias e pelo número de atletas. Como há dois tipos de exercícios realizados na mesma máquina, o exercício do abdutor e do glúteo, teremos número de ciclos realizados no exercício do abdutor é de $116640(60 \times 9 \times 216)$ e o número de ciclos realizados no exercício de glúteo é de 105300 (60 × 9 × 195), totalizando 221940 ciclos de flexão. 
Portanto, o número real ciclos de flexões calculado a partir de dados estatísticos levantados na academia é maior que do resultado teórico encontrado pela equação experimental de Niemam. Desta forma, o fenômeno que levou a falha foi mesmo fadiga por flexão, embora ocorrida prematuramente. o que nos leva a concluir que a máquina apolete teve um projeto inadequado.

Para evitar que ocorra a ruptura do cabo após um curto período de tempo de uso, pode-se abordar o equipamento de dois modos distintos:

Sem modificar o projeto atual, apenas substituindo ou alterando componentes, como o cabo de enrolamento normal pelo enrolamento tipo lang, que devido ao fato de possuir uma grande superfície de contato entre os elementos enrolados, apresenta alta aderência e uma maior flexibilidade, que é o esforço crítico atuante.

Ou ainda, aumentar o diâmetro das polias em relação as utilizadas atualmente, uma vez que isto reduz o ângulo de flexão do cabo, e consequentemente, reduz a tensão atuante no mesmo, aumentando sua vida em fadiga.

Modificando o projeto atual, remodelando a máquina e evitando, assim, que uma mesma região do cabo sofra movimentos rotacionais em sentidos contrários (horário e anti-horário). Isto poderia ser feito, utilizando-se polias apoiadas nas laterais da máquina, e não no centro, com um cabo passando por cada uma, de modo que, dependendo do exercício realizado, resultaria sempre em um cabo tracionado e o outro livre, e assim, cada cabo seria enrolado em um único sentido.

\section{CONCLUSÃO}

Da análise de falha descrita neste trabalho, conclui-se que:

O cabo de aço da máquina apolete está superdimensionado para o carregamento pretendido, tendo um coeficiente de segurança de aproximadamente 20 vezes para solicitação estática; e 7 vezes para tensão de flexão.

O projeto da máquina tornou-se inadequado para uso de qualquer cabo de aço flexível, em virtude dos movimentos invertidos que sofre, tornando necessário que os projetos de máquinas deste tipo tenham apenas movimentos alternados.

O número real de flexões é maior que o valor estimado a partir da equação experimental de Niemam, o que evidencia falha por fadiga. O cabo de aço rompeu por fadiga devido ao elevado número de flexões ao qual o mesmo é submetido, que somado ao agravante dos movimentos invertidos, faz com que haja uma falha prematura.

\section{REFERÊNCIAS}

ARAGÃO, V. T. S. SANTOS, O. A. SILVA, A. S. GRIZA, S. Análise de Falha em Arame de Cerca Elétrica, 68o Congresso Anual da ABM - Internacional, 30 de julho a 2 de agosto de 2013, Belo Horizonte, MG, Brasil, PP. 1833-1841.

BERNARDINI, P. A. N. Notas de aulas da disciplina Plasticidade: Resistência dos Metais. Notas de aulas digitalizadas, 2001

BERNARDINI, P. A. N. Notas de aulas da disciplina Mecânica da Fratura e Fadiga. Notas de aulas digitalizadas, 2001. 
BUDYNAS, R. G. NISBETT, J. K. Elementos de Máquinas de Shigley: projeto de engenharia mecânica. Rio de Janeiro: LTC - Livros Técnicos e Científicos S.A., 2011.

COELHO, V. Movimentadores de Materiais. Florianópolis: ETF/SC. P. 69-92, 1988.

CUNHA, L. B. Elementos de Máquinas. LTC Editora, 2005.

JONES, D. R. H. Engineering Materials 3: Materials failure Analysis - Case studies and Design Implications. Pergamon Press, 1993.

PETERKA, P. KRESAKK, J. KROPUCH, S. FEDORKO, G. MOLNAR, V. VOJTKO, M. Failure analysis of hoisting steel wire rope, Engineering Failure Analysis 45 (2014) 96-105.

TORKAR, M. ARZENSEK, B. Failure of crane wire rope, Eng. Fail. Analysis 9 (2002) 227-233.

VERNON, P. J. MACKIN, T. J. Fadigue Failure Analysis of a Leg Pres Exercise Machine. Emgineering Failure Analysis, v.6, p.1-12, 1999.

XIANG, L. WANG, H. Y. CHEN, Y. GUAN, Y. J. WANG, Y. L. DAI, L. H. Modeling of multi-strand wire ropes subjected to axial tension and torsion loads, International Journal of Solids and Structures 58 (2015) 233-246. 